\title{
O LIBERALISMO POLÍTICO DE JOHN RAWLS: A MISSÃO DE EDUCAR A JUVENTUDE PARA A DEMOCRACIA NO SÉC. XXI
}

\author{
Neuro Jose Zambam ${ }^{1}$
}

Ricardo de Oliveira de Almeida ${ }^{2}$

\begin{abstract}
Resumo
O objetivo desta investigação é apresentar a compreensão de liberalismo político de John Rawls como fundamento da democracia e para a educação da juventude brasileira neste período de insegurança jurídica, constringimento social e instabilidade política. A opção metodológica priorizou a análise da introdução da obra $o$ liberalismo político a parir da qual são apresentadas as principais citações para a fundamentação dos temas selecionados. A conclusão está ancorada sobre a necessidade de atualização contínua das convicções e do exercício da democracia, especialmente por meio do debate público, da participação e revitalização da legislação. O liberalismo político retrata convicções necessárias à educação da juventude brasileira em vista da apreensão da democracia como um valor moral e o seu exercício cotidiano.
\end{abstract}

Palavras-chave: Construtivismo político. Democracia. Educação. Liberalismo. John Rawls.

\section{INTRODUÇÃO - UMA TEORIA DA JUSTIÇA COMO EQUIDADE}

A publicação da obra "Uma teoria da justiçą" de John Rawls em 1971 nos Estados Unidos foi decisiva para o estudo e o debate público dos assuntos relacionados às questões das desigualdades e injustiças no mundo que demandam a busca de soluções justas a fim de evitar a desintegração social, a ampliação das divisões ou divergências que ameaçam a estabilidade social e podem conduzir à extinção da democracia como o sistema político com as melhores condições e recursos para uma organização social segura. $\mathrm{O}$ contexto da época sinalizava para o fim da "Guerra fria" e a necessidade de outro referencial para uma convivência pacífica, assim como, das relações internacionais.

\footnotetext{
${ }^{1}$ Pós-Doutor em Filosofia pela PUCRS. Professor do Programa de Pós-graduação Stricto Sensu em Direito da Faculdade Meridional. Professor do Curso de Direito (graduação e especialização) da Faculdade Meridional. Membro do Grupo de Trabalho, Ética e cidadania da ANPOF (Associação Nacional dos Programas de Pós-graduação em Filosofia). Pesquisador da Faculdade Meridional. Coordenador do Grupo de Pesquisa: Multiculturalismo, minorias, espaço público e sustentabilidade. Líder do Centro brasileiro de pesquisas sobre a Teoria da justiça de Amartya Sen: interfaces com direito, políticas de desenvolvimento e democracia. E-mail: nzambam@imed.edu.br.

${ }^{2}$ Mestrando em direito pela Faculdade Meridional. E-mail: ricardo-almeidaa@hotmail.com.

${ }^{3}$ As referências da obra Uma Teoria da Justiça no decorrer desta exposição será UTJ.
} 
A contundente crítica de Rawls ao utilitarismo e ao intuicionismo demonstra a insuficiência dessas abordagens para propor formas de relacionamento pautadas pelos referenciais da legalidade, pela moralidade democrática, pela mediação institucional e pela efetiva valorização, participação e cooperação dos membros ativos da sociedade.

O prefácio à edição brasileira de UTJ expõe com riqueza de detalhes os objetivos da obra de Rawls comprometidos com a justiça como equidade e, especificamente, a sua profissão de fé na democracia constitucional. A sua obra original é referência para a reflexão jurídica e política que visam a superação das graves deficiências e dos dilemas sociais da atualidade, especificamente, as desigualdades que estão na origem da instabilidade em nível nacional e internacional. Ratifica o Autor,

A razão principal para buscar essa alternativa é, no meu modo de pensar, a fragilidade da doutrina utilitarista como fundamento das instituições da democracia constitucional. Em particular, não acredito que o utilitarismo possa explicar as liberdades e direitos básicos dos cidadãos como pessoas livres e iguais, uma exigência de importância absolutamente primordial para uma consideração das instituições democráticas. Utilizei uma visão mais geral e abstrata da ideia do contrato social usando para isso a ideia de posição original. Uma explicação das liberdades e direitos básicos, e também de sua prioridade, foi o primeiro objetivo da justiça como equidade. Um segundo objetivo foi integrar essa explicação a um entendimento da igualdade democrática, o que conduziu ao princípio da igualdade equitativa de oportunidades e ao princípio da diferença (RAWLS, 2000, p. XIV).

A ampla aceitação da obra - seja nos níveis acadêmicos seja nos políticos, associações, igrejas, profissionais de outras áreas e sua imediata tradução para diversos idiomas e países, inclusive aqueles sem uma sólida tradição democrática - sinaliza a carência de uma proposta atualizada para abordar temas relevantes do período de forma não restritiva, mas integrada com as mudanças e os acontecimentos globais, bem como capaz de analisar de forma rigorosa e comprometida com a democracia os temas nacionais da época. Outrossim, representou o esgotamento das referências pautadas prioritariamente na tradição utilitarista, especificamente para justificar o modelo capitalista ou pela atuação exclusiva do Estado como ator da organização social.

O vigor das conclusões que foram apresentadas na obra, acompanhadas pela seriedade da exposição contribuiu para fomentar o debate político sobre as principais questões da democracia a partir do ideal de igualdade e cooperação entre os membros ativos da sociedade e, posteriormente, entre os povos. A escolha dos princípios da justiça para elaborar um ordenamento seguro das sociedades a partir de uma posição original representou, do ponto de vista simbólico, a demonstração de como é possível estruturar instrumentos de participação, seja para a eleição de metas e objetivos válidos para todos, seja para que estes obtenham a aceitação e o apoio da ampla maioria da população. A sua efetivação por meio das instituições básicas, organizações representativas e estruturas de justiça eficazes demonstra o vigor da democracia e as condições de transformação social em vista do bem comum.

O contexto da obra e o período histórico do seu surgimento justificam o seguinte destaque, "A teoria da 
justiça renovou os debates nos termos da filosofia política. Denso e compacto, Rawls fomentou o diálogo entre as mais diversas disciplinas e entre profissionais das diferentes áreas, sendo hoje considerado um clássico da filosofia contemporânea” (ZAMBAM, 2015, p. 66).

A breve referência à UTJna introdução desta exposição tem como objetivo situar o tema da democracia na obra de Rawls e sua relevância para a educação das novas gerações para a cidadania. Os temas a seguir estão fundados na introdução da obra "O liberalismo político ", que obteve o reconhecimento do público, entre outros motivos, pela capacidade de Rawls avaliar, esclarecer e, por vezes, corrigir a exposição anterior. A "profissão de fé" na democracia que caracteriza os estudos do mencionado autor, é atualizada, revisada e recebe um conjunto de novas referências para trazer mais consistência aos temas da tradição e, de forma integrada com a problemática da época, antevê o cenário do futuro, especificamente a necessária educação para as convicções básicas da estrutura democrática.

A estabilidade política, a tolerância, as condições de participação, o financiamento das campanhas eleitorais, os acordos ou consensos, o funcionamento das instituições, a razão pública, a paz, as relações internacionais e o drama da pobreza ou das desigualdades contemplam os temas prioritários escolhidos por Rawls em vista da necessidade de maior justiça social.

A educação da juventude para a democracia é um imperativo global, principalmente, no Brasil. As conquistas amplamente evidenciadas por diversos meios demandam o seu maior conhecimento, atualização e correção de rumos. As crises, limites e deficiências experimentadas no Brasil clamam aos líderes e às instituições a educação das futuras gerações para que não amarguem retrocessos ainda maiores, destruição das instituições ou mesmo a negação de suas referências básicas, como, por exemplo, o valor da pessoa e o exercício da liberdade. $\mathrm{O}$ $L P$ é um caminho privilegiado para se compreender a importância - formal e substancial - da democracia, seja pelo seu caráter didático e pedagógico, seja pelo seu vigor instrumental, para exercitar essa missão em nível político, jurídico e institucional.

A escolha dessa metodologia, isto é, a abordagem da obra $L P$ a partir da sua introdução e a limitação dos comentadores consultados, visa oferecer uma orientação para a sua leitura e o seu conhecimento considerando os temas relevantes ali destacados. As referências selecionadas do interior da obra são consideradas relevantes para a compreensão e a visualização da sua arquitetura a fim de orientar o leitor para a apreensão e o conhecimento da sua cartografia filosófica e jurídica. A visualização da obra por meio dessa dinâmica confirma o valor universal da democracia e a necessidade de assumi-la como hábito na conduta social.

A compreensão mais acurada da obra pode ser visualizada a partir da análise dos principais pilares da democracia e, especialmente, a decisiva contribuição da Reforma para o exercício da tolerância e a liberdade de consciência. $\mathrm{O}$

${ }^{4}$ As referências à obra $\mathrm{O}$ liberalismo político no decorrer desta exposição será $L P$. 
entendimento sem preconceitos desta obra é um desafio para a reflexão política e a renovação da democracia.

\section{O LIBERALISMO POLÍTICO}

A reflexão inaugurada pelo $L P$ é uma referência para os debates sobre a igualdade, as dificuldades do pluralismo, a estabilidade social, o conteúdo das legislações, o funcionamento das instituições e outros ramos da democracia constitucional. A exposição sistemática do conteúdo sobre a proposta de um liberalismo político é antecedido pelo debate em universos diferentes, acadêmicos ou não. $\mathrm{O}$ texto aqui analisado é o resultado de um conjunto de conferências que abordaram temas presentes na UTJ e outros acrescidos a fim de ampliar o seu entendimento considerando os novos contextos. A observação que sinaliza algumas revisões operadas em relação à UTJestá destacada na seguinte afirmação do pensador:

Os objetivos dessas conferências são bem diferentes. Observe que, em meu resumo dos objetivos de Teoria, a tradição do contrato social aparece como parte da filosofia moral e não faz distinção alguma entre filosofia moral e política. Em teoria, uma doutrina moral da justiça de alcance geral não se distingue de uma concepção estritamente política de justiça. $\mathrm{O}$ contraste entre doutrinas filosóficas e morais abrangentes e concepções limitadas ao domínio do político não é de grande relevância. No entanto, essas distinções e ideias afins são fundamentadas nas conferências aqui apresentadas (RAWLS, 2000b, p. 23).

O liberalismo político é a apresentação de uma concepção de justiça atualizada e contextualizada num período histórico caracterizado por inúmeras disputas entre países e blocos econômicos e ideológicos bem definidos, que, embora cambaleantes e com evidentes transformações internas e externas, influenciavam áreas importantes e estratégicas no mundo. A profissão de fé na democracia é uma característica de Rawls e será ampliada nesta exposição.

O liberalismo político não é uma doutrina metafísica ou um plano de governo que visa a solução de problemas imediatos e pontuais, mas uma proposta de concepção política dirigida inicialmente às sociedades democráticas caracterizadas pelo pluralismo. Essa é uma premissa fundamental para pensar, propor, escolher, concretizar e avaliar as condições de justiça social, ou mesmo, conforme destacado no preâmbulo da Constituição Brasileira, a efetivação do bem comum5.

O ordenamento social seguro pressupõe a capacidade e as condições para a estabilidade política considerando as incontáveis controvérsias ou divergência existentes no interior das sociedades. A apropriação dessa obra precisa antever essa característica como um fato contingente, isto é, não pode ser negado, excluído, combatido ou desprezado. A assertiva de Rawls foi demonstrar essa dinâmica: "O liberalismo político pressupõe que, para propósitos políticos, uma pluralidade de doutrinas abrangentes e razoáveis, e, ainda assim, incompatíveis, seja o resultado normal do exercício da razão humana dentro da estrutura das instituições livres de um regime

\footnotetext{
${ }^{5}$ Art. 30 "São poderes da união, independentes e harmônicos entre si, o legislativo, o executivo e o judiciário. IV- promover o bem de todos, sem preconceitos de origem, raça, sexo, cor, idade e quaisquer outras formas de discriminação”.
} 
democrático constitucional" (RAWLS, 2000b, p. 24).

O núcleo de orientação para a compreensão dos acréscimos em relação à UTJ e as posteriores ampliações e eventuais correções está nessa capacidade de percepção de que a organização justa, segura e estável das sociedades contemporâneas, especificamente as democrático-constitucionais, ocorre a partir dessa dinâmica sabendo que o núcleo de orientação é político e não metafísico. Esclarecendo: "A ambiguidade de Teoria está eliminada agora, e a justiça como equidade é apresentada, desde o começo, como uma concepção política de justiça” (RAWLS, 2000b, p. 25).

A estrutura da compreensão do liberalismo político, como proposto, percorreu uma extensa trajetória de debates, embates e construção de acordos. O exercício do debate público, seja acadêmico ou não, envolveu a necessidade de reconfigurar e, eventualmente, renunciar a interesses ou convicções individuais, institucionais e políticos em vista dos novos contextos e atores. Rawls enumera os três eventos que foram determinantes para a filosofia moral e política: A Reforma do Século XVI, o desenvolvimento do Estado Moderno e o desenvolvimento da Ciência Moderna (RAWLS, 2000b, p. 30).

Os acontecimentos históricos destacados possuem significado simbólico e político simultaneamente e foram responsáveis por outros de igual relevância e repercussão, bem como, contribuíram para a formatação de novas concepções e destacada importância, conforme sublinha o mencionado filósofo: "Na verdade, o sucesso do construtivismo liberal manifestou-se como a descoberta de uma nova possibilidade social: a possibilidade de uma sociedade pluralista estável e razoavelmente harmoniosa" (RAWLS, 2000b, p. 32).

O liberalismo político, segundo Rawls, não tem a pretensão de abarcar a totalidade das demandas sociais e solucioná-las, mas ser uma alternativa que demonstre a necessidade e as condições para um ordenamento social estável, justo e seguro. Neste estágio da exposição, confirma-se a autonomia, a identidade e as convicções desse autor, não dissociadas da tradição da Teoria do Contrato Social, mas profundamente integradas ao contexto histórico atual, isto é, diferente da tradição que apresenta um liberalismo abrangente. Esse, sustenta o liberalismo político.

A citada expressão anterior - liberalismo político - tem como objetivo congregar e integrar num sistema de cooperação a diversidade de concepções existentes no interior das sociedades. As suas divergências, embora às vezes profundamente contraditórias, não podem ser motivo para a instabilidade social. O traço norteador dessa dinâmica de convivência equitativa e tolerante é o necessário compromisso de todas com as orientações centrais da democracia. A união em torno desse sistema é consequência do exercício concreto da razão pública. A ampla diversidade de concepções e instituições independentes e cooperativas, contribui substancialmente com a vitalidade de uma sociedade democrática.

A proposta de Rawls visa um construtivismo político a partir de uma clara concepção de pessoa como 
sujeito ativo e portador de uma concepção de bem e de sociedade cooperativa e comprometida com o bem comum. As doutrinas, com suas divergências e concordâncias, endossam um regime democrático constitucional exercitando seus valores no cotidiano da rotina social. Explicitamente destaca-se a tolerância e o debate público.

\section{O PLURALISMO E A RAZÃO PÚBLICA}

A constituição da estabilidade das sociedades democráticas é a maior preocupação de Rawls no decorrer da obra $L P$ porque as divergências e contradições são um paradoxo que pode limitar, impedir e até suplantar o seu funcionamento. A inversão dessa dinâmica de organização social do ponto de vista da sua constituição originária é impossível. O fato do pluralismo é dado e não uma contingência histórica.

A percepção mais aprofundada do fenômeno, isto é, a sua afirmação, demonstra que é impossível, além de uma atitude de ingenuidade, propor uma igualdade aritmética porque, essa, negaria a natureza e a atuação social do homem que é motivada por interesses diversos e objetivos nunca tacitamente convergentes. O contrário disso seria a proposição de uma autorregulação das sociedades, tanto interna quanto em nível externo. Esta, por sua vez, implicaria a existência de desigualdades que seriam consequência da ausência de controle e organização do seu próprio funcionamento.

Ambas as expectativas estão em contradição porque a diversidade é a característica das sociedades democráticas. Rawls enfatiza essa realidade e manifesta a tensão existente no cotidiano das democracias contemporâneas: "[ ... ] o problema do liberalismo político consiste em compreender como é possível existir, ao longo do tempo, uma sociedade estável e justa de cidadãos livres e iguais profundamente divididos por doutrinas religiosas, filosóficas e morais razoáveis, embora incompatíveis" (RAWLS, 2000b, p. 25). As proposições que visem solucionar problemas ou interferir na organização social devem contemplar esse contexto.

A organização das sociedades marcadas pelo pluralismo em todas as esferas sociais precisa buscar um conjunto de referências para a sua estabilidade por um período prolongado. A convicção de Rawls é no sentido de que a estabilidade seja formatada no âmbito político e não no moral. A consequência dessa referência demanda a educação para o exercício da democracia conjugado com o compromisso político dos cidadãos.

O discurso sobre a natureza da razão pública e sua finalidade, seja da estabilidade política, seja da identidade social, inclui admitir que essa tem o conteúdo essencial para organizar e articular os planejamentos sociais e o funcionamento das principais instituições a fim de construir o bem de todos. Os cidadãos, enquanto membros ativos da comunidade, têm capacidade moral, política e intelectual para atuar no seu interior.

A razão, sendo pública, é a razão de ser de uma sociedade democrática. É a razão do público em vista do seu bemestar. Rawls sublinha os seus três sentidos: trata-se da razão do público, seu objeto é o bem do público e as questões de justiça fundamental e sua natureza e conceitos são públicos. Essa é uma compreensão ideal para 
mostrar como seria um ordenamento equitativo seguro e estável. As pessoas, enquanto membros de uma sociedade, aderem a essas orientações (RAWLS, 2000b, p. 262).

A compreensão de uma sociedade democrática como um sistema de cooperação entre pessoas livres e iguais - como Rawls sublinha de forma convicta e insistente no decorrer da sua obra, especialmente no $L P$ supõe o reconhecimento de que o conteúdo da razão pública pertence a todos os cidadãos que conjuntamente exercem a liberdade, assim como, assumem os ideais de justiça. Explica Oliveira:

Na medida em que a razão pública é compartilhada por todos, publicamente, pode-se falar de uma democracia deliberativa, que se mostra como a melhor forma de governo do povo, pelo povo e para o povo. A ideia de razão pública é, portanto, correlata às ideias da prioridade do justo sobre o bem e do consenso sobreposto para a realização do liberalismo político (OLIVEIRA, 2003, p. 33).

O reconhecimento do pluralismo como a característica genuína da identidade das sociedades democráticas contemporâneas é o fenômeno que mais preocupa as questões de justiça, especificamente a construção das condições para a convivência pacífica e tolerante, bem como impulsiona a formatação de mecanismos para a solução dos problemas decorrentes desse mesmo fenômeno. Por exemplo, a sua própria negação, o distanciamento de pessoas, povos e culturas especificamente pela ampliação das desigualdades sociais e econômicas, ou mesmo, a sobreposição unilateral de interesses individuais ou de grupos.

A insistente condenação das inúmeras formas de injustiça social foi esclarecida na permanente afirmação da necessidade de justiça social para todos. O destaque, com igual prioridade, à equidade demonstra, tanto do ponto de vista simbólico quanto político, que essa meta é possível e irrenunciável. A conjugação ou administração de concepções e interesses divergentes é próprio da atuação política nas democracias, o que exige cuidado e perspicácia. A avaliação da justiça social depende da efetivação dos critérios de equidade.

A atuação política, orientada pelos princípios da justiça, tem entre suas metas a equalização das desigualdades e a prevenção dos problemas que possam ameaçar a sua estabilidade social. A assertiva de Rawls está em reconhecer o fato do pluralismo como parte da cultura política das sociedades democráticas, conforme destaca: "No liberalismo político, o dualismo entre o ponto de vista da concepção política e os muitos pontos de vista das doutrinas abrangentes não é um dualismo originado na filosofia. Origina-se, ao contrário, na natureza especial da cultura política democrática marcada pelo pluralismo razoável (RAWLS, 2000b, p. 29).

Sabendo que o pluralismo não é um problema grave para a equalização das relações sociais, a razão pública democrática precisa orientar a conduta política dos cidadãos. Sem essa condição, a dicotomia amplia seus horizontes e impede a construção de acordos que tenha como meta um ordenamento seguro. $\mathrm{O}$ esclarecimento do conteúdo da razão pública é um exercício didático e pedagógico permanente em vista do bem comum, entendido como um objetivo do Estado e das instituições sociais. Nesse contexto cabe ressaltar: 
O tema da razão pública é essencial para a compreensão e justificação do liberalismo político porque representa a síntese das opções dos cidadãos livres e iguais de uma sociedade democrática. Rawls entende que a razão pública é aceita pelos membros da sociedade e orienta, limita e impulsiona a participação efetiva nos seus destinos. Ela representa as motivações mais importantes que formam a identidade de um povo, o seu governo, as instituições e o funcionamento geral. A afirmação da razão pública é essencial para a legitimidade das sociedades democráticas e o equilíbrio da sua organização social sabendo das inúmeras divergências existentes no seu interior (ZAMBAM, 2015, p. 148).

A participação social dos cidadãos, cuja identidade está ancorada na sua condição de livres e iguais, ultrapassa o formalismo para experimentar a dinâmica da razão pública numa sociedade democrática orientada por princípios aos quais é dada a adesão dos cidadãos individualmente e das instituições, especificamente destacase a missão da família na transmissão dos valores democrático-liberais e na educação das gerações futuras.

Assinala-se, especialmente na dimensão jurídica, a responsabilidade do Supremo Tribunal Federal para a compreensão, o esclarecimento, a interpretação e a aplicação do conteúdo da razão pública seja para decidir as questões e problemas mais importantes da sociedade, seja para garantir a estabilidade institucional e em vista da justiça social sabendo das divergências internas e da necessidade de salvaguardar o valor de cada cidadão.

\section{A PESSOA E AS CONDIÇÕES DE COOPERAÇÃO}

A compreensão de Rawls sobre a pessoa, a sua realização humana e a responsabilidade de participação social está relacionada com as condições para a sua integração e cooperação no cotidiano da sociedade na condição de cidadão livre e igual. Essa afirmação é essencial para entender a obra $L P$ e a integração e atuação de cada indivíduo na realidade, seja no ambiente onde vive, seja nas diversas esferas do ordenamento social. A condição igual de cidadania é um valor essencial para Rawls, conforme assinala: "A ideia do construtivismo político deve ser familiar a todos os que conhecem a posição original da justiça como equidade, ou uma estrutura semelhante" (RAWLS, 2000b, p. 28).

A estruturação da concepção de justiça depende da ação e participação ativa dos cidadãos. O fato do pluralismo está representado, também, na multiplicidade de concepções morais, políticas e religiosas existentes no interior de cada sociedade que impactam diretamente sobre a formação moral e a conduta política do conjunto da comunidade. A percepção assinalada por Rawls sobre as doutrinas afirmando que nenhuma delas é professada de forma abrangente, designa a necessidade de antever as capacidades das pessoas, seja individualmente, seja no seu conjunto, de formatarem as condições para a equidade social.

A posição original ${ }^{6}$ é o espaço de representação dos cidadãos livres e iguais, membros de uma sociedade democrática caracterizada pelo pluralismo. Na proposta de um liberalismo político, os cidadãos atuam em vista de 
uma sociedade bem-ordenada a partir de uma base constitucional. As diferenças existentes na sociedade impulsionam a construção de consensos em vista da justiça equitativa ou da estabilidade social. O homem é um ser capaz, como sublinha,

A terceira caraterística do construtivismo político é utilizar uma concepção bem complexa de pessoa e sociedade para dar forma e estrutura à sua construção. Como vimos, o construtivismo político vê a pessoa como membro de uma sociedade política entendida como um sistema equitativo de cooperação social de uma geração para outra. Supõe que as pessoas disponham de duas faculdades morais conjugadas a essa ideia de cooperação social - a capacidade de ter senso de justiça e uma concepção de bem (RAWLS, 2000b, p. 138).

O conteúdo dos princípios da justiça evidencia a identidade da pessoa como um agente ativo para a organização social, bem como as prerrogativas essenciais para o seu agir. Inicialmente, destaca-se o direito a um amplo sistema de liberdades como a condição para a concretização das liberdades básicas acessíveis a todos. Nesse tema específico, o acento às liberdades políticas demonstra a afirmação da democracia constitucional como o sistema de organização social com as melhores condições para reconhecer, valorizar e contribuir para a afirmação da pessoa e sua importância no ordenamento social. Em síntese, o liberalismo político é pensado para as pessoas, ou seja, os cidadãos.

A afirmação do direito é outra dimensão básica para a compreensão do valor e da missão da pessoa nascida e identificada com a trajetória de uma sociedade concreta. Rawls, por vezes, destaca que não escolhemos estar nesse ambiente com essas condições e circunstâncias. Contudo, inseridos nela, precisamos agir como pessoas integradas e buscar a justiça e as condições de existência. Essa é uma dimensão que não se prende a uma estimativa teórica, mas supõe as condições necessárias para o exercício dos direitos e liberdades básicas.

A representação do cidadão na posição original objetivando uma sociedade bem-ordenada na forma de uma base constitucional demanda a observação da necessária contribuição valiosa das pessoas. Por fim, é a pessoa com sua identidade e relacionada com as demais que traz sentido ao modelo de justiça, apresentado por Rawls, na forma de um liberalismo político.

O segundo princípio, no qual ressalta as condições de justiça a partir de um critério de ordenamento das desigualdades, tem seu foco especialmente concentrado na dignidade das pessoas e nas condições concretas para participar de forma livre e autônoma dos destinos da sociedade. A prioridade aos menos favorecidos é, tanto de ponto de vista conceitual como da respectiva concepção política, a demonstração da necessária opção pelo valor e pela busca da dignidade humana, começando pelos normalmente excluídos ou classificados em posições secundárias.

A exposição do conteúdo e a conclusão relacionada ao significado moral e político da pessoa para a

\footnotetext{
6 "A posição original (original position) é a situação hipotética na qual as partes contratantes (representando pessoas racionais e morais, isto é, (livres e iguais) escolhem, sob um "véu de ignorância' (viel of ignorance), os princípios de justiça que devem governar a estrutura básica da sociedade (basic structure of society)". (OLIVEIRA, 2003, p. 14).
} 
teoria da justiça como equidade pode ser destacada com a seguinte conclusão:

Além disso, os dois princípios expressam uma forma igualitária de liberalismo em virtude de três elementos. São eles: a) a garantia do valor equitativo das liberdades políticas, de modo que não sejam puramente formais; b) igualdade equitativa (e, é bom que se diga, não meramente formal) de oportunidades; e, finalmente, c) o chamado princípio da diferença, segundo o qual as desigualdades sociais e econômicas associadas aos cargos e posições devem ser ajustadas de tal modo que, seja qual for o nível dessas desigualdades, grande ou pequeno, devem representar o maior benefício para os menos privilegiados da sociedade (RAWLS, 2000b, p. 48).

A condição de igualdade proposta por Rawls para os cidadãos livres e iguais responde ao fato do pluralismo e a necessidade de demonstrar como a justiça social é possível, apesar das desigualdades e diferenças que não podem ser extintas ou alienadas. A opção pelos direitos é a característica da democracia que consagra a condição de sujeito de direitos como um princípio igualitário para todos. $\mathrm{O}$ acesso a cargos e posições, juntamente, com a opção pelos menos favorecidos como critério de igualdade, não as extingue ou nega, mas permite desigualdades justas.

A percepção dessa dinâmica social evidencia as condições e possibilidades de abordar o valor da pessoa a partir de sua dignidade individual, bem como a sua filiação cultural, o seu pertencimento a uma sociedade específica e suas prerrogativas futuras. As condições de estabilidade social e política das sociedades democráticas e constitucionais requer a capacidade de integração das pessoas a partir das suas diferenças e características. A negação dessa prerrogativa é a exclusão da sua dignidade e das condições de justiça social, especificamente, a partir das desigualdades equitativas.

\section{A TOLERÂNCIA E OS CONSENSOS}

A teoria da justiça como equidade proposta por Rawls, especialmente o liberalismo político, busca uma forma de equalizar as contradições existentes no interior das sociedades. O exercício da tolerância e a construção de consensos dependem das possibilidades de efetivação desse objetivo. Ressalta-se: "A afirmação das desigualdades de ordem filosófica, religiosa e moral como traço característico das sociedades contemporâneas desafia os cidadãos para a criação das condições de convivência no mesmo espaço social” (ZAMBAM, 2015, p. $145)$.

Os exemplos de intolerância na história que podem demonstrar as dificuldades para a concretização da equidade ou mesmo a superação de concepções e práticas de intolerância foram evidenciadas envolvendo fatos e personagens: "Lutero e Calvino eram tão dogmáticos e intolerantes quanto a Igreja Católica havia sido" (RAWLS, 2000b, p. 31). Essa é a demonstração da real dificuldade das democracias do passado e dos contextos da atualidade: "Trata-se de um problema de justiça política, não de um problema sobre o bem supremo" (RAWLS, 2000b, p. 33). 
A compreensão das desigualdades como constitutivas da ordem social não permite justificá-las, mas ordená-las, conforme Rawls esclarece nos princípios. Nesse sentido, e para dar conta da necessária estabilidade política de longo prazo, é necessário afirmar que quanto maiores as desigualdades maiores as injustiças. Na esfera moral e nas teorias da justiça, as desigualdades, especificamente aquelas que ameaçam a boa convivência entre as pessoas ou o funcionamento razoável das instituições sociais, não encontram nenhuma justificativa ou legitimidade.

A avaliação da justiça demanda a superação das barreiras - culturais e/ou institucionais - que impedem a cooperação, a participação, o exercício da liberdade e outras referências da democracia constitucional que podem ser sintetizadas pelo individualismo moral que está na origem de inúmeras situações que constrangem a tradição e impedem projetos que buscam o bem comum. $O$ valor da pessoa e sua integração social na perspectiva consagrada como sujeito de direitos precisa ser recíproca e conduzir para metas comuns. Esse conflito é conclusivo para o liberalismo político,

Num regime democrático, a base da tolerância e da cooperação social fundamentada no respeito mútuo corre perigo quando essas distinções não são reconhecidas; pois, quando isso acontece e esses ideais e modos de vida assumem uma forma política, os termos equitativos de cooperação são formulados de maneira estreita, e a cooperação livre e voluntária entre pessoas com diferentes concepções de bem torna-se impossível” (RAWLS, 2000b, p. 428).

Considerando o fato do pluralismo de ordem filosófica, religiosa e moral, "o liberalismo político não é um liberalismo abrangente" (RAWLS, 2000b, p. 35) do que deriva a necessidade de compreender e concretizar o valor da tolerância como uma das dimensões essenciais da razão pública democrática e, com o objetivo de reafirmar a convicção, a demonstração da capacidade humana de superar divergências e fanatismos que comprometam negativamente a saudável convivência entre as pessoas nas sociedades democráticas.

A consequência dessa cooperação é elaborada por Rawls no consenso sobreposto (overlapping consensus) que representa as condições para a estabilidade democrática ante o fato da pluralidade divergente. A convergência, por sua vez, ocorre a partir de uma concepção de justiça para as sociedades democráticas e de pessoa na sua condição de membro ativo ${ }^{7}$.

O objetivo do consenso sobreposto é abarcar as questões mais importantes da sociedade democrática. Por esse motivo, é profundo e utópico. A unidade social é construída a partir de uma concepção de justiça aceita por todos e orientada pelas instituições sociais justas. Logo, a meta é, "[...] construir uma concepção política democrático liberal abrangente e razoável, isto é, aceita por significativa parcela da sociedade e das diversas formas de pensar presentes no seu interior" (ZAMABM, 2015, p. 131).

\footnotetext{
7 "A justiça como equidade elabora as ideias fundamentais de sociedade enquanto sistema equitativo de cooperação, acrescendo a isso a concepção de pessoa como livre e igual. Essas ideias são consideradas centrais para o ideal democrático. [...] A segunda
} vol.10, nº. 03, Rio de Janeiro, 2017.pp.1500-1516 
Os desafios da unidade e estabilidade social e política, no atual contexto, encontram na ideia de um consenso as referências básicas para a estruturação das condições de justiça que seja comum a todos. As divergências, nesta orientação, não são extintas, mas integradas numa estrutura social abrangente e justa, não excludente, mas capaz de ordenar as diferenças e esclarecê-las em vista da justiça social.

Já o consenso constitucional, que é outra prerrogativa de Rawls em vista da equalização das desigualdades, não é profundo e contempla um conjunto de procedimentos materializados na Constituição de um país cujo conteúdo visa o ordenamento e a atuação de um governo democrático. A opção por acordos de maior ou menor profundidade precisa obter a anuência das doutrinas existentes na sociedade que sejam razoáveis e orientadas por princípios e convicções aos quais as pessoas possam aderir. Por exemplo, a tolerância e o respeito às decisões por maioria. Em síntese:

[...] O Consenso Constitucional, isto é, a Constituição, é colocado como o primeiro estágio. Uma Constituição formaliza os princípios liberais de justiça política, estabelece o sistema eleitoral dentro dos parâmetros democráticos e ordena os conflitos políticos e de outra natureza no interior da sociedade, garantindo, assim, a estabilidade social e política. Por essa razão o consenso constitucional não é profundo e é alcançado quando as concepções abrangentes dos cidadãos passam a ser razoáveis, com o que o pluralismo passa a ser razoável. Os princípios liberais que organizam uma sociedade regulada já dão conta de parte do consenso constitucional (ZAMBAM, 2015, p. 142).

As democracias contemporâneas têm na arquitetura legal ${ }^{8}$ o seu referencial mais importante para as garantias dos Direitos Fundamentais, das instituições e do próprio funcionamento das sociedades, tanto no âmbito interno, quanto em nível internacional. Nesse sentido - e destacando novamente o pluralismo como realidade -, afirma-se que os acordos e consensos precisam plasmar as relações políticas e institucionais visando a equidade social.

O justo funcionamento da estrutura básica da sociedade, conforme entende Rawls, depende fortemente, dentre outros fatores, da capacidade dos cidadãos enquanto livres e iguais de conjugar a cooperação social, a participação política e a construção de acordos ou consensos. A diminuição dos níveis de desigualdade orientada pelo princípio da diferença e das garantias de liberdade, efetiva-se com mais intensidade quando ancorada na razão pública democrática, cujos consensos são amplamente esclarecidos, acordados e concretizados.

\section{A SOCIEDADE BEM-ORDENADA}

A correção das desigualdades injustas que representam um compromisso de grave responsabilidade para as sociedades democráticas é a preocupação substancial de Rawls desde UTJ. O termo equidade, nesse contexto, é simbólico, mais do que quantitativo, das dificuldades de propor uma orientação completa ou conclusiva,

consideração é a de que diferentes interesses sociais e econômicos dão sustentação a concepções liberais diferentes. As diferenças entre as concepções expressam, em parte, um conflito entre esses interesses" (RAWLS, 2000b, p. 214). 
sabendo das incoerências e incongruências que dificultam e, por vezes, impedem a justiça social. A descrição desse contexto é marcado pela emoção e pelo realismo político e doutrinal do filósofo.

O grave problema a que me referi - é preciso que eu explique - diz respeito à ideia pouco realista de 'sociedade bem-ordenada', tal como aparece em Teoria. Uma característica essencial de uma sociedade bem-ordenada associada à justiça como equidade é que todos os seus cidadãos endossam essa concepção com base no que agora chamo de doutrina filosófica abrangente. Aceitam que seus dois princípios de justiça estejam fundamentados nessa doutrina (RAWLS, 2000b, p.24).

O conjunto da obra de Rawls, particularmente $L P$, é a expressão da sua confiança nas condições de um ordenamento seguro, duradouro e equitativo das sociedades democráticas. A escolha dos princípios da justiça na posição original para orientar a organização e o funcionamento das instituições sociais é uma dimensão básica para o entendimento das condições de justiça e da concepção de sociedade. Uma sociedade bem-ordenada é consequência da cooperação de todos. Nesse sentido,

Os princípios têm como objetivo primordial e irrenunciável dar sustentação à estrutura básica da sociedade, ordenando as instituições num esquema de cooperação. Faz parte das metas atribuir direitos e deveres às instituições com a respectiva distribuição de benefícios e encargos sociais. Às situações e ações particulares dos indivíduos não são diretamente aplicados os princípios (ZAMBAM, 2015, p. 106).

A necessidade de corrigir as desigualdades que ameaçam a estrutura básica da sociedade implica a opção por um conjunto de referências que conjuguem direitos e responsabilidades básicas para todos. Nesse sentido, os princípios contemplam um conjunto de liberdades básicas e critérios de igualdade que sejam compatíveis com as possibilidades de participação, cooperação e integração dos cidadãos. O enunciado dos princípios evidencia que a igualdade proposta por Rawls não é aritmética, mas, o seu ordenamento, cujo resultado não é igualitário, pode ser considerado justo. Os princípios da justiça de John Rawls são:

(a) todas as pessoas têm igual direito a um projeto inteiramente satisfatório de direitos e de liberdades básicas iguais para todos, projeto este compatível com todos os demais; e, neste projeto, as liberdades políticas, e somente estas, deverão ter seu valor equitativo garantido.

b) as desigualdades sociais e econômicas devem satisfazer dois requisitos: primeiro, devem estar vinculadas a posições e cargos abertos a todos, em condições de igualdade equitativa de oportunidades; e, segundo, devem representar o maior benefício possível aos membros menos privilegiados da sociedade (RAWLS, 2000b, p, 47).

Uma sociedade bem-ordenada depende da avaliação, compreensão, publicidade e, especificamente, das possibilidades de efetivação do conteúdo dos princípios, sem os quais não se pode falar em justiça social. Nessa reflexão, a liberdade foi esclarecida, contudo, cabe uma maior atenção às condições de igualdade a partir dos benefícios aos menos privilegiados da sociedade. A não eliminação das desigualdades não significa a sua legitimidade ou concordância, mesmo em situações de complexas ou similares.

A proposição de Rawls em vista de um ordenamento justo está direcionado para a avaliação das condições de justiça e a consequente justificativa das desigualdades a partir das condições de existência e

8 "Como ideal, a concepção de cidadania num regime constitucional indica como as coisas devem ser" (RAWLS, 2000b, p. 9). vol.10, no. 03, Rio de Janeiro, 2017.pp.1500-1516 
integração daqueles que mais necessitam ou estão em situações mais vulneráveis. Afirma: "O elemento constitucional essencial em questão é o de que, abaixo de certo nível de bem-estar material e social, e de treinamento e educação, as pessoas simplesmente não podem participar da sociedade como cidadãos, e muito menos como cidadãos iguais" (RAWLS, 2000b, p. 213).

As políticas públicas são indicativos essenciais para que esta proposta seja percebida concretamente no cotidiano das relações sociais. O Estado, seja pela sua responsabilidade legal seja pelo seu alcance político, tem a obrigação mais abrangente de organizar as ações em vista da igualdade social, mas também é missão das demais instituições, personalidades, líderes, associações e cidadãos em geral a integração dos cidadãos democráticos livres, iguais e cooperativos no conjunto da sociedade. A concretização dos princípios depende desse dinamismo.

A síntese sobre os critérios de igualdade foi esclarecida por Rawls no decorrer da sua exposição de forma a eleger desigualdades justas num conjunto de orientações que conjugam a cooperação entre os que estão em melhores e piores condições, ou seja, os primeiros justificam os seus ganhos na medida em que tenham contribuído para a melhoria dos demais. O princípio da diferença, nessa dinâmica, emerge como o critério para, simultaneamente, ordenar e corrigir as desigualdades 9 (RAWLS, 2000b, p. 335).

A necessidade de um ordenamento justo das relações políticas e sociais (sociedade bem-ordenada) é um objetivo que preocupa os responsáveis pela sua organização, especificamente os legisladores que pautam sua ação pela moralidade pública e pelo combate às injustiças. Rawls sabe que sua proposta é um ideal, no entanto, assinala que precisa de condições em vista de uma proposição equitativa, nesse sentido, por exemplo, propõe o recurso que chamou de véu de ignorância para que sua proposta seja possível. Em relação a esse tema e sua abrangência esclarece Oliveira:

A sociedade bem-ordenada (well-ordened-society) é aquela que é efetivamente regulada por uma concepção política e pública de justiça, na qual cada indivíduo aceita - e sabe que todos os seus cidadãos também aceitam - os mesmos princípios de justiça e, portanto, os termos equitativos de cooperação social, assim como as suas instituições políticas, sociais e econômicas, que são por todos publicamente reconhecidas como justas (OLIVEIRA, 2003, p. 14).

A estruturação de uma sociedade bem-ordenada é essencial e de responsabilidade de cada pessoa porque é parte integrante da sua estrutura e com capacidade de cooperação, participação e atuação ativa e permanente. Assegura-se, no conjunto do liberalismo político, uma concepção política e social da justiça em permanente evolução. A integração e interação de grupos, associações e demais atores afirma a identidade democrática de uma sociedade liberal assim entendida e, por consequência, que dispõe dos mecanismos e recursos da própria democracia para resolver seus problemas e melhor organizar o seu funcionamento. Nesse

\footnotetext{
9 "A estrutura básica deve permitir desigualdades organizacionais e econômicas, desde que estas melhorem a situação de todos, inclusive a dos menos privilegiados, e desde que essas desigualdades sejam compatíveis com a liberdade igual e a igualdade equitativa de oportunidade". (RAWLS, 2000b, p. 335).
} 
sentido, a apresentação de uma solução concreta para o gritante problema das desigualdades é uma contribuição destacada e reconhecida, em variados ambientes e instituições, de John Rawls para a humanidade.

A arquitetura do $L P$, desde a introdução, prima pelo amplo sistema de cooperação e pelo princípio da equidade como norteadores do comportamento social. A conduta humana, de quem depende a organização social em primeira instância, é marcada pela autonomia em relação a si e profundamente comprometida com os demais. A razão pública traz a identidade democrática na formação e na ação de cada cidadão e, posterior a esse cenário, cada um age e reconhece no outro a mesma capacidade. A relação de reconhecimento e a cooperação na condição de cidadão livre e igual, a partir da preferência aos menos favorecidos, impulsiona e consagra a justiça como equidade.

\section{CONCLUSÃO}

A necessária educação para a democracia em seus diferentes níveis é uma tarefa permanente desde o seu surgimento porque o contexto social é dinâmico e toma novas formas e clama pela reconfiguração da atuação dos seus líderes, pela renovação das formas de pensar e agir, bem como por representar um dos pilares mais agudos do sistema em questão, pela invenção de novos meios de participação e, mesmo, a sua reinvenção.

A afirmação dessa prerrogativa no conjunto da obra do Gigante de Harvard clama para a leitura serena e crítica do $L P$ considerando, primeiro, o seu valor original, e, posteriormente, associado à percepção visionária do panorama, por vezes confuso, que vislumbrou e registrou os principais atores e as problemáticas futuras que mudariam substancialmente, segundo nossa percepção, a compreensão, a atuação e o exercício do poder no Século XXI.

A tarefa educativa que, no geral, associa habilidade didática e rigor pedagógico, quando integrada à democracia, no atual momento histórico, se agiganta considerando as mazelas que em muitas situações ameaçam a sua base conceitual e corrompem a sua prática. A correção de rumos demanda a atualização da afirmação que todos os cidadãos são membros ativos da sociedade na condição de livres e iguais com plena capacidade de cooperação.

O contexto atual nos incita a professar, juntamente com Rawls, a convicção sobre a democracia como o melhor sistema para a organização das sociedades. Essa é uma conquista irrenunciável da humanidade. O liberalismo político é uma proposição necessária para justificar, atualizar e reinventar essa afirmativa, bem como a sua prática.

A percepção de Rawls quanto à democracia apontou para os novos direitos e os novos atores que demandariam o esforço das novas gerações em vista da justiça equitativa em meio à complexidade contemporânea. Especificamente quando refere aos temas que envolvem raça, etnia e gênero, vislumbrou os 
dilemas de nossa época e desafiou para a reinvenção da teoria e dos princípios. A intensidade da sua obra contemplou também a citação de pensadores emergentes que seriam fundamentais para a ampliação da crítica à democracia, como, Amartya Sen.

O conhecimento da obra de Rawls é uma oportunidade de perceber as dificuldades de fazer justiça em sociedades democráticas marcadas pelo pluralismo. A preocupação de propor as condições para uma sociedade bem-ordenada posicionando os seus membros ativos na posição original, mesmo que de forma hipotética, em condições de escolher os princípios da justiça para orientarem o funcionamento das instituições mais importantes da sociedade, assim como, os demais mecanismos de equalização e a afirmação dos tradicionais valores da democracia, prioritariamente, a participação e a tolerância, demonstra o necessário compromisso dos cidadãos e a necessidade de internalização da identidade democrática na sua conduta moral e na organização social.

Os cidadãos concebidos na sua identidade genuína de pessoas livres e iguais demonstra a afirmação do seu valor próprio e da sua autonomia. A condição de igualdade dos membros ativos da sociedade reconhece, promove e respeita a individualidade de forma a superar o individualismo moral e a atuação política pautada pelo autointeresse. Afirma-se a necessidade de fomentar a cooperação como demonstração do exercício da cidadania na condição de sujeito de direitos, referência básica do homem livre numa democracia.

A reconstrução da tradição democrática desde a Grécia Clássica, a atenção prioritária sobre a Reforma como a referência para a consagração da pluralidade e da tolerância como constituintes das sociedades e a explicitação dos princípios com o conteúdo necessário e suficiente para um ordenamento seguro, estável e duradouro do ordenamento social, consagra a obra de Rawls no seu tempo e, conjugada às novas conquistas da reflexão humana, é uma referência para as demandas do atual momento não menos desfiador, contudo, mais complexo, conhecido e necessitado de justiça como equidade. A missão de educar as gerações futuras, especialmente no Brasil, para este dinamismo está posta.

\title{
JOHN RAWLS'S POLITICAL LIBERALISM: HOW TO EDUCATE YOUTH FOR THE XXI CENTURY'S DEMOCRACY
}

\begin{abstract}
The purpose of this research is to provide an understanding of political liberalism of John Rawls as the foundation of democracy and education of Brazilian youth in this period of legal uncertainty, social constraint and political instability. The methodological option focused on the analysis of "Political Liberalism" in its Introduction to show the main quotes for the selected themes in this paper. The conclusion is based on the need for continuous updating of the convictions and the exercise of democracy, especially through public debate, participation and the law's improvement. Political liberalism brings which convictions are necessary to Brazilian youth's education in order to understand the importance of democracy as a moral value and its daily exercise.
\end{abstract}


Keywords: Political Constructivism. Democracy. Education. Liberalism. John Rawls.

\section{REFERÊNCIAS BIBLIOGRÁFICAS}

DE VITA, Álvaro. A justiça igualitária e seus críticos. 2. ed. São Paulo: Martins Fones, 2007.

OLIVEIRA, Nythamar de. RAWLS. Rio de Janeiro: Jorge Zahar, 2003.

RAWLS, John. Uma teoria da justiça. Tradução de Almiro Pisetta e Lenita M. R. Esteves. São Paulo: Martins Fontes, 2000.

O liberalismo político. 2. ed. Tradução de Dinah de Abreu Azevedo. São Paulo: Ática, 2000.

O direito dos povos. Tradução de Luis Carlos Borges. São Paulo: Martins Fontes, 2001.

2012

Conferências sobre a história da filosofia política. Tradução de Fábio M. Said. São Paulo: Martins Fontes,

SENADO FEDERAL. Constituição da República Federativa do Brasil. Brasília, Senado Federal, 2008.

ZAMBAM, Neuro José. Introdução à teoria da justiça de John Rawls. 2. ed. Rio de Janeiro, Lumen Juris, 2015.

Trabalho enviado em 17 de setembro de 2016.

Aceito em 05 de março de 2017. 